\title{
AN ALGORITHM FOR DESIGN OF BRICK LINING FOR IRRIGATION CHANNELS
}

\author{
Akshay Chaudhary ${ }^{1}$, Amanpreet Singh ${ }^{2}$ \\ ${ }^{1,2}$ M.E Student, Irrigation and Hydraulics Department, PEC University of Technology, Chandigarh, India
}

\begin{abstract}
Irrigation water is a costly commodity, and as such, there should be no wastage during its carriage from the reservoirs to the fields. Most of the canals constructed to carry this irrigation water, are unlined, and hence; a large part of it is lost in percolation and absorption as seepage loss (25-50\% of the water is lost in seepage). The seepage can be avoided by lining the canals. The conveyance of water for spatial water balance has complex hierarchy extending upon huge canals hundreds of kilometers along with branches etc, to small channels, distributaries in delivering the water to soil in the cropped field that act as storage units for the plants. The networking of canal system is complex in nature. So, in order to solve such complex nature of problem, a computer algorithm based on $C++$ language for the design and economics of lined channel is developed in the present study.
\end{abstract}

Keywords: Algorithm, Canals, $C++$, Percolation and Seepage loss

\section{INTRODUCTION}

With the unfortunate partition of the country, and with the creation of Pakistan, 31\% of the country's irrigated area stood transferred to Pakistan, as against the transfer of only $18 \%$ of its population. Thus, India was left high and dry with only $19 \%$ of its cropped area under irrigation, facing acute famines and food grain shortages. Large-scale efforts were then made to develop and harness our vast water resources, so as to ensure collection of water during monsoon, and its subsequent use for irrigation during non-monsoon period. Several dams have therefore been planned and constructed across various rivers to store water during rainy season to reduce the fury of floods, and long canal network constructed to move down the stored water during dry weather to the fields, to ensure irrigation supplies to the crops [1].

In the present study, the networking of canal system is complex in nature. In order to solve such complex nature of the problem a computer algorithm based on $\mathrm{C}++$ language for the design and economics of lined channel is developed. The programme in C++ language is easy to compile and build [2]. In computer algorithm following design calculations are going to be done:

- Design of Channel cross section

- Cost estimates for brick lining

In the computer algorithm, the minors and the watercourses are also to be lined in order to increase the efficiency of irrigation so that the outlet discharge factor could be maintained at the head of the minor. Less time is required for irrigating a particular area of land, as by lining losses are less and discharge almost remains constant so that more area can come under irrigation, which on the other hand can increase the crop yield.

So, for the financial viability of lining, it is necessary to analyze the extra capital cost of providing lining on one hand, and on the other hand an evaluation of the benefits of lining is done. Almost all the benefits of lining of canal can be evaluated in terms of capitalized value. For lining to be economically feasible, the capitalized value of benefits should be equal to or greater than extra cost involved in providing lining.

\section{METHODOLOGY AND ANALYSIS}

Design of irrigation channels involves the conditions of steady and uniform flow. A steady and uniform flow is said to prevail, when the discharge is same at all the sections in a particular length of the channel under consideration and the depth of flow does not change.

$\mathrm{C}++$ programming language was considered as just an enhanced version of the $\mathrm{C}$ programming language with a few extra keywords, but it is not so. It is one of the well designed and widely accepted object oriented programming language. Though C++ has no provision for input/output, it of course has to be dealt with at some point or other. There is not much use in writing a programme that spends all its time telling itself a secret. Each operating system has its own facility for inputting and outputting data from and to the files and devices. It's a simple matter for a system programmer to write a few small programs that would link to the C++ compiler for particular operating systems input/output facilities. In input file certain value is assigned to the constants, which after calculation gives us the value of unknowns in the output file [2]. 
The flow chart shown in figure 1 gives us a brief idea about design of channel cross section and cost estimates for brick lining calculation. Based upon this flowchart an algorithm was developed in which input data file consists of manning's coefficient (n), discharge (Q), slope (S) and length of canal (L) and on the other hand output data file consists of depth (d), hydraulic mean depth $(\mathrm{R})$, velocity $(\mathrm{V})$, area $(\mathrm{A})$, wetted perimeter $(\mathrm{P})$, Berm width, number of bricks $(\mathrm{N})$, quantity of cement $(\mathrm{C})$, quantity of sand $(\mathrm{M})$ and total cost $(\mathrm{Zz})$.

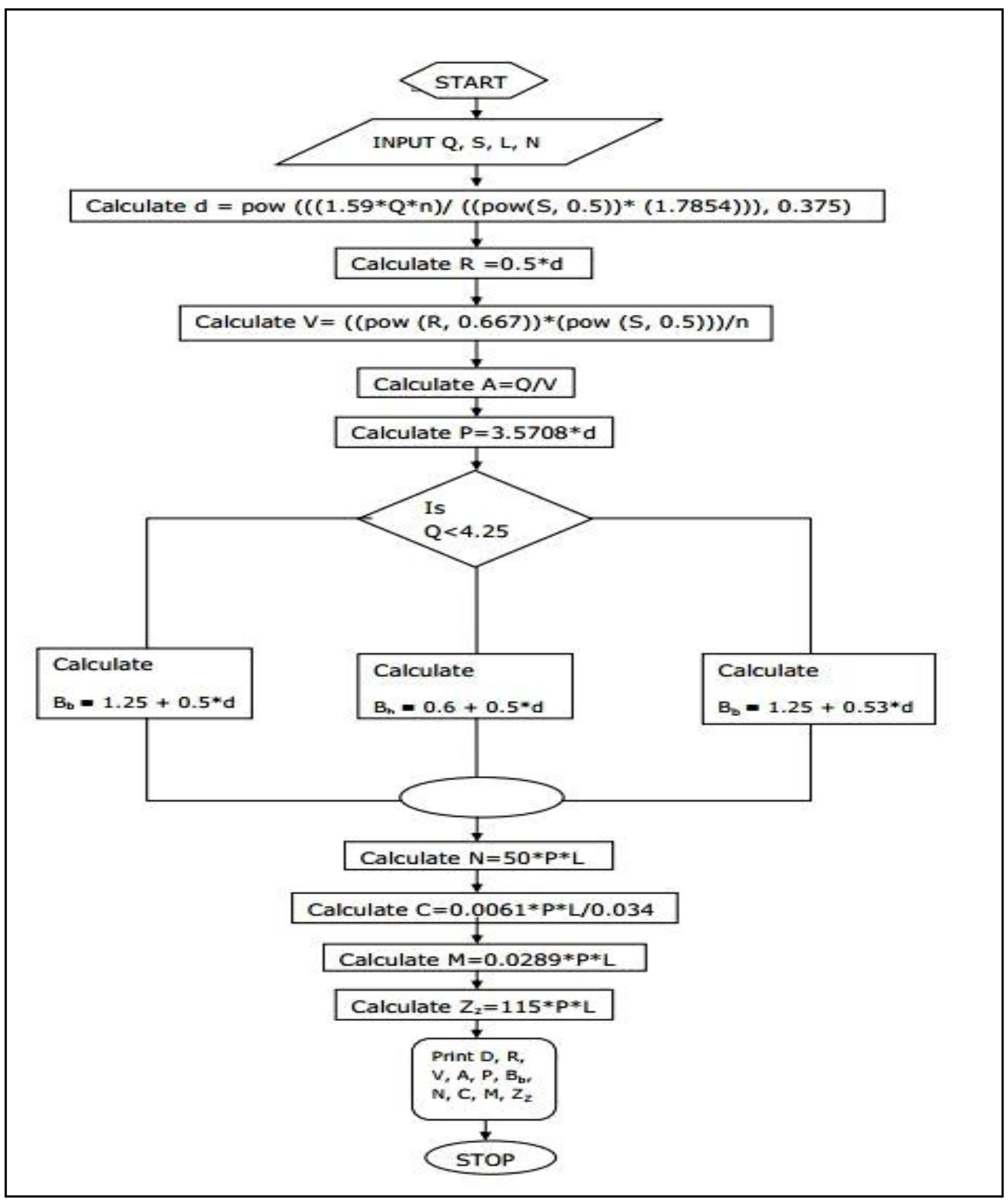

Fig 1: Flowchart 


\section{RESULTS AND DISCUSSION}

In this study optimal design parameters are calculated for the following cases:

\subsection{Case 1: Keep $S, L$ and $N$ constant, vary $Q$.}

In this case keeping $\mathrm{S}=0.0002, \mathrm{~L}=10000 \mathrm{~m}, \mathrm{n}=0.016$ and varying the discharge (shown in table 1), optimal cost of canal and optimal parameters are found out and their variation studies with the variation of discharge. It is obvious that for higher discharges bigger sections will be required resulting in increase of cost of canal.

Table 1: Keep S, L and N constant, vary Q.

\begin{tabular}{|c|c|c|c|c|c|c|c|}
\hline $\begin{array}{l}\mathrm{Q} \\
\text { varies }\end{array}$ & d & $\mathrm{R}$ & V & A & $\mathrm{P}$ & $\mathrm{Bb}$ & $\mathrm{Zz}$ \\
\hline 0.3 & 0.64 & 0.32 & 0.41 & 0.73 & 2.3 & 0.92 & $\begin{array}{l}2.74 \mathrm{E}+0 \\
06\end{array}$ \\
\hline 1 & 1 & 0.5 & 0.56 & 1.8 & 3.6 & 1.1 & $\begin{array}{l}4.3 \mathrm{E}+00 \\
6\end{array}$ \\
\hline 5 & 1.84 & 0.92 & 0.83 & 6.0 & 6.55 & 2.2 & $\begin{array}{l}7.86 \mathrm{E}+0 \\
06\end{array}$ \\
\hline 10 & 2.38 & 1.19 & 0.99 & 10.1 & 8.5 & 2.44 & $\begin{array}{l}1.02 \mathrm{E}+0 \\
07\end{array}$ \\
\hline 30 & 3.6 & 1.8 & 1.3 & 23 & 12.8 & 3.04 & $\begin{array}{l}1.54 \mathrm{E}+0 \\
07\end{array}$ \\
\hline 50 & 4.35 & 2.18 & 1.5 & 33.7 & 15.5 & 3.42 & $\begin{array}{l}1.86 \mathrm{E}+0 \\
07\end{array}$ \\
\hline 100 & 5.64 & 2.82 & 1.76 & 56.7 & 20.1 & 4.07 & $\begin{array}{l}2.42 \mathrm{E}+0 \\
07\end{array}$ \\
\hline
\end{tabular}

Figure 2.1 shows the variation of optimal depth of flow "d" with discharge. Depth of flow increases with increase in discharge. Figure 2.2 show that velocity increases with increase in value of discharge. Figure 2.3 show that the area of canal increases as discharge increases and is higher for high discharge values. Figure 2.4 show the variation of optimal cost of canal with discharge. It is observed that the optimal cost of canal increases almost linearly with the increase in discharge.

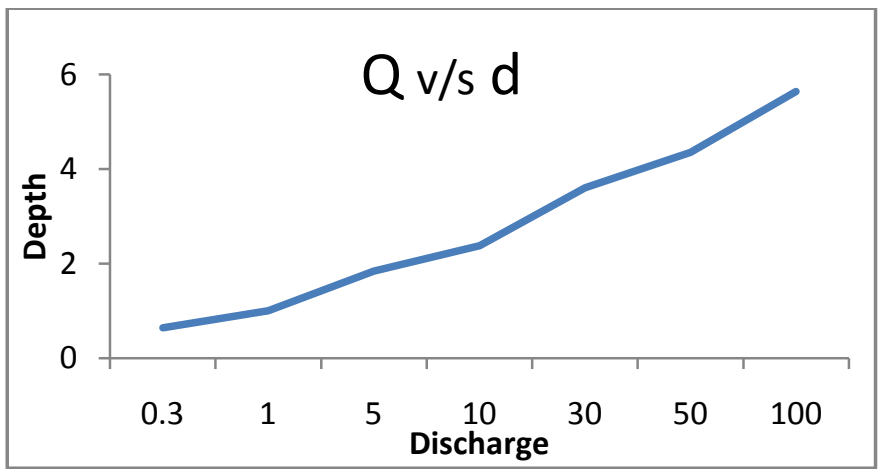

Fig 2.1: $Q$ vs d

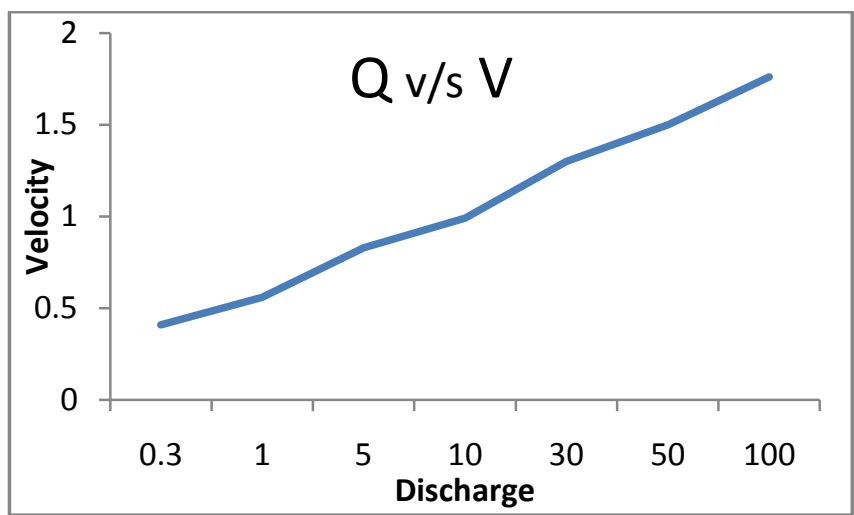

Fig 2.2: $\mathrm{Q}$ vs $\mathrm{V}$

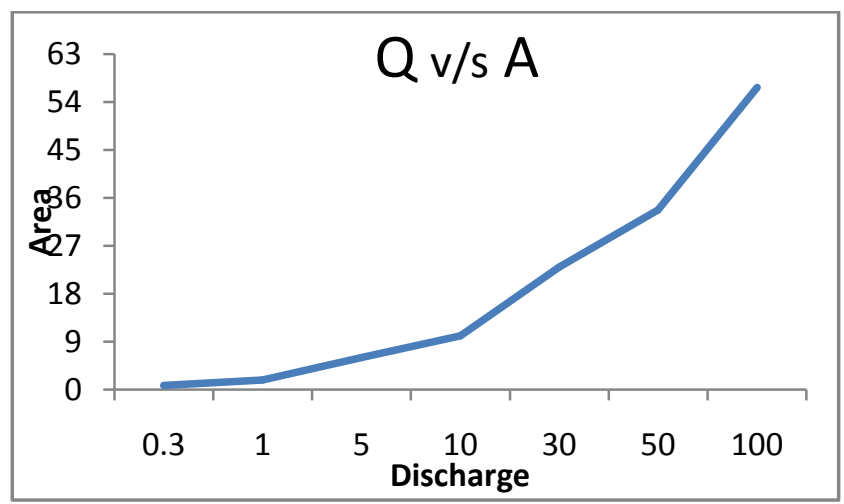

Fig 2.3: $Q$ vs $A$

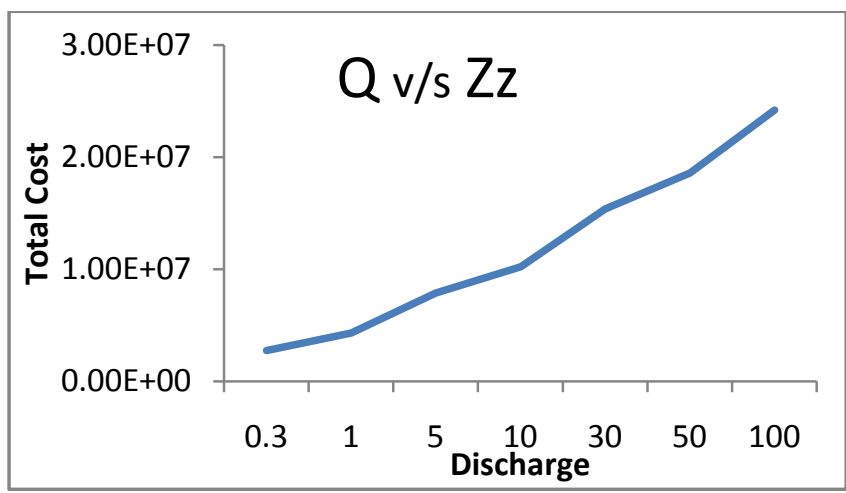

Fig 2.4: $Q$ vs $Z_{Z}$

The optimal value in figures 2.1, 2.2, 2.3, 2.4 can be used to find out the optimal depth, velocity, area and cost of canal for a particular value of discharge.

\subsection{Case 2: Keep Q, $\mathrm{L}$ and $n$ constant, vary Slope.}

In this case $\mathrm{Q}=10$ cumecs, $\mathrm{L}=10000 \mathrm{~m}, \mathrm{n}=0.016$ and varying the ground slope (shown in table 2), optimal cost of canal and optimal parameters are found out and their variation studies with the variation of ground slope. 
Table 2

\begin{tabular}{|c|c|c|c|c|c|c|c|}
\hline $\begin{array}{c}\mathrm{S} \\
\text { varies }\end{array}$ & $\mathrm{d}$ & $\mathrm{R}$ & $\mathrm{V}$ & $\mathrm{A}$ & $\mathrm{P}$ & $\mathrm{B}_{\mathrm{b}}$ & $\mathrm{Z}_{\mathrm{z}}$ \\
\hline 0.0001 & 2.7 & 1.35 & 0.77 & 13.1 & 9.7 & 2.60 & $1.16 \mathrm{E}+007$ \\
0.0002 & 2.4 & 1.2 & 0.99 & 10.1 & 8.5 & 2.44 & $1.02 \mathrm{E}+007$ \\
0.0003 & 2.2 & 1.1 & 1.15 & 8.66 & 7.9 & 2.35 & $9.44 \mathrm{E}+006$ \\
0.0004 & 2.1 & 1.05 & 1.3 & 7.77 & 7.5 & 2.30 & $8.95 \mathrm{E}+006$ \\
0.0005 & 2.0 & 1.0 & 1.4 & 7.15 & 7.2 & 2.25 & $8.60 \mathrm{E}+006$ \\
\hline
\end{tabular}

Figure 2.5 shows the variation of optimal depth of flow "d" with ground slope. Depth of flow decreases with increase in ground slope. Figure 2.6 show that velocity increases with increase in ground slope. Figure 2.7 show that the area of canal decreases as slope increases. Figure 2.8 show the variation of optimal cost of canal with discharge. It is observed that the optimal cost of canal decreases almost linearly with the increase in ground slope.

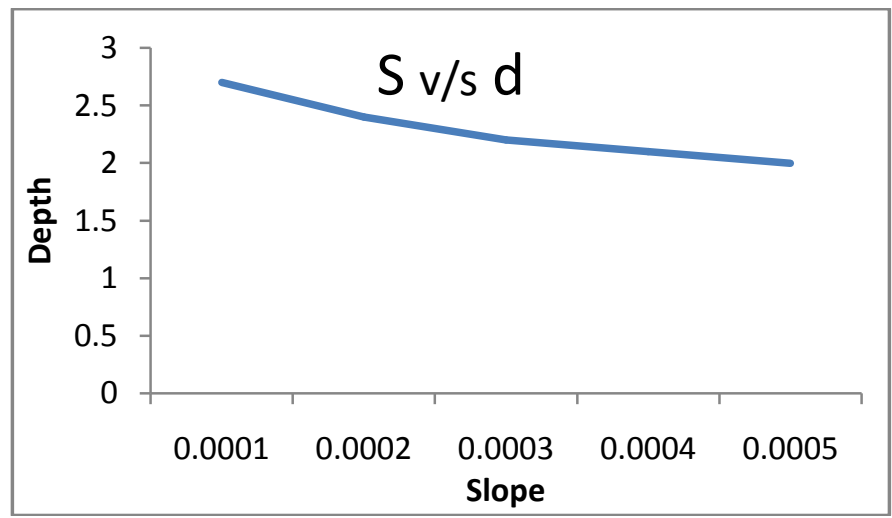

Fig 2.5: $\mathrm{S}$ vs d

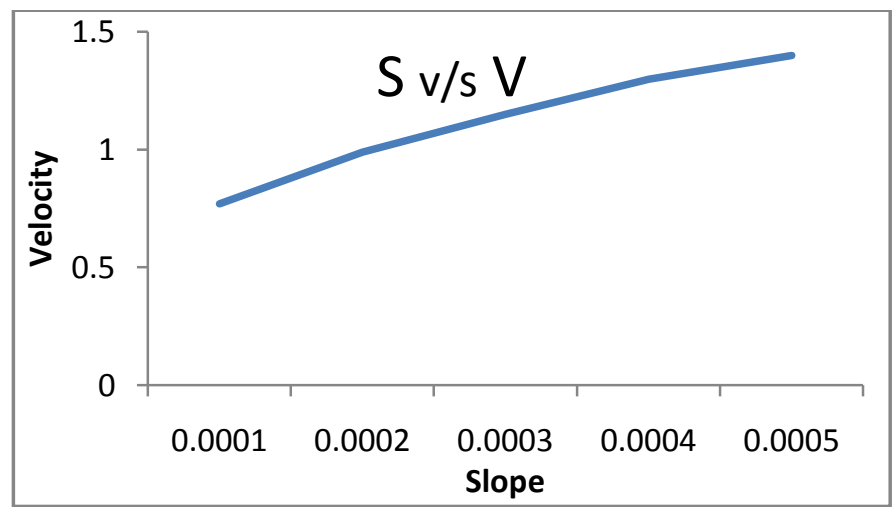

Fig 2.6: $\mathrm{S}$ vs $\mathrm{V}$

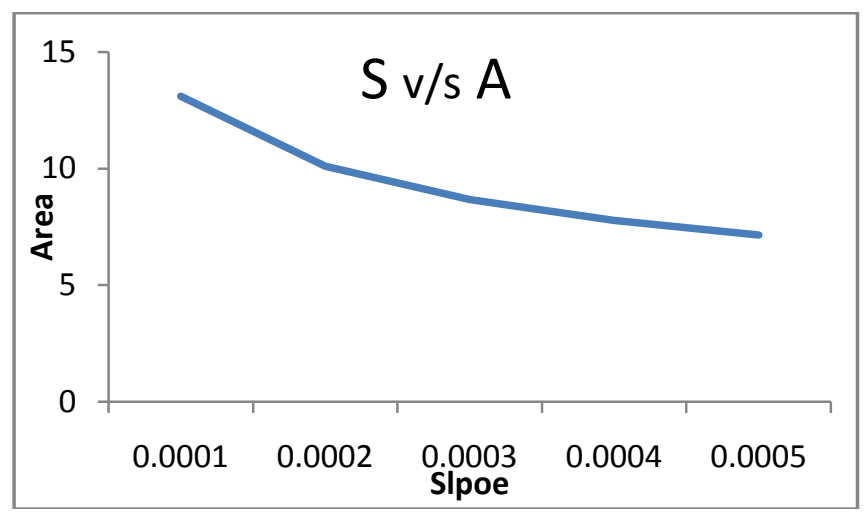

Fig 2.7: $\mathrm{S}$ vs A

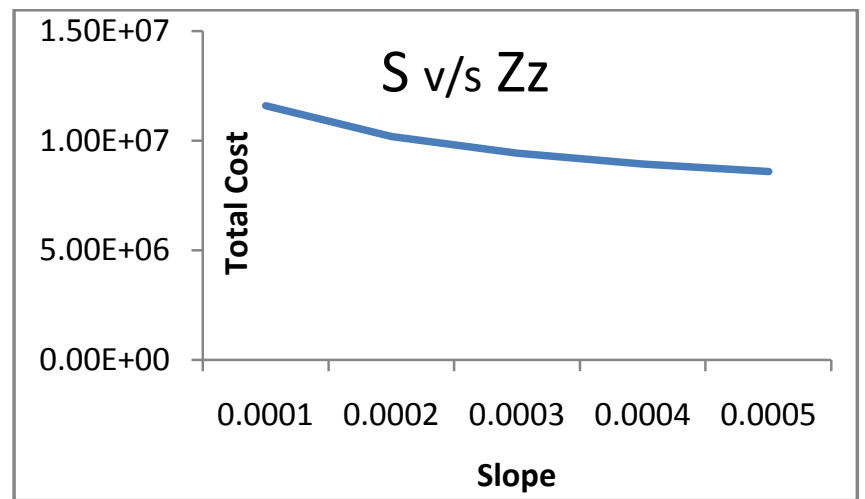

Fig 2.8: $S$ vs $Z_{Z}$

\subsection{Case 3: Keep Q, S and n constant and vary $L$.}

Keeping $\mathrm{Q}=10$ cumecs, $\mathrm{S}=0.0002, \mathrm{n}=0.016$ and varying length of canal (shown in table 3), optimal cost are found out and their variation with L. Figure 2.9, 2.10, 2.11, 2.12 shows that the optimal cost increases with the increase in length of canal.

Table 3

\begin{tabular}{|c|c|c|c|c|c|c|c|}
\hline $\begin{array}{c}\mathrm{L} \\
\text { varies }\end{array}$ & $\mathrm{d}$ & $\mathrm{R}$ & $\mathrm{V}$ & $\mathrm{A}$ & $\mathrm{P}$ & $\mathrm{B}_{\mathrm{b}}$ & $\mathrm{Z}_{\mathrm{z}}$ \\
\hline 10000 & 2.4 & 1.2 & 0.99 & 10.1 & 8.5 & 2.44 & $1.02 \mathrm{E}+007$ \\
20000 & 2.4 & 1.2 & 0.99 & 10.1 & 8.5 & 2.44 & $2.04 \mathrm{E}+007$ \\
30000 & 2.4 & 1.2 & 0.99 & 10.1 & 8.5 & 2.44 & $3.06 \mathrm{E}+007$ \\
40000 & 2.4 & 1.2 & 0.99 & 10.1 & 8.5 & 2.44 & $4.08 \mathrm{E}+007$ \\
50000 & 2.4 & 1.2 & 0.99 & 10.1 & 8.5 & 2.44 & $5.10 \mathrm{E}+007$ \\
\hline
\end{tabular}




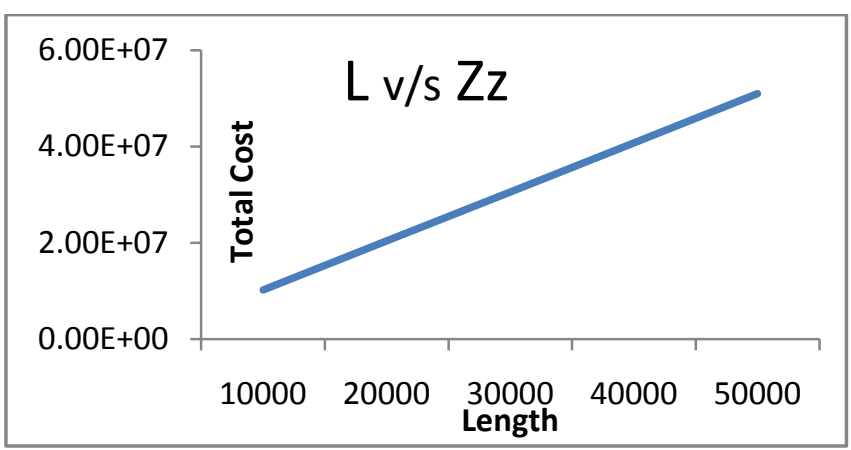

Fig 2.9: $\mathrm{L}$ vs $\mathrm{Z}_{\mathrm{Z}}$

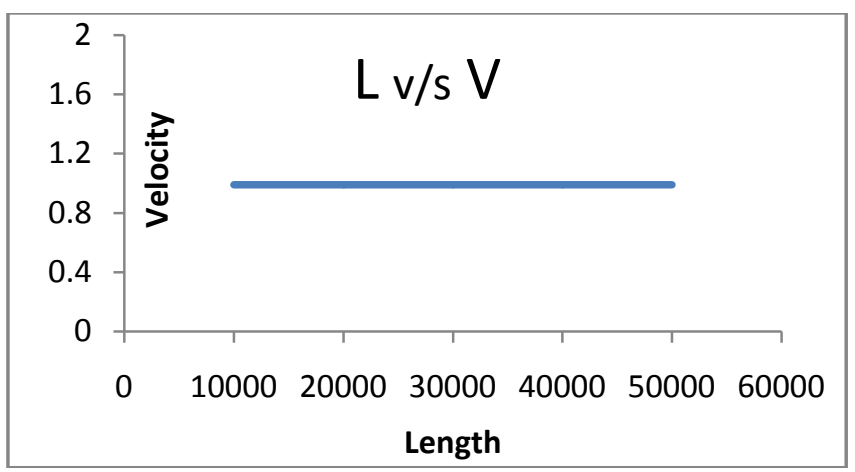

Fig 2.10: L vs V

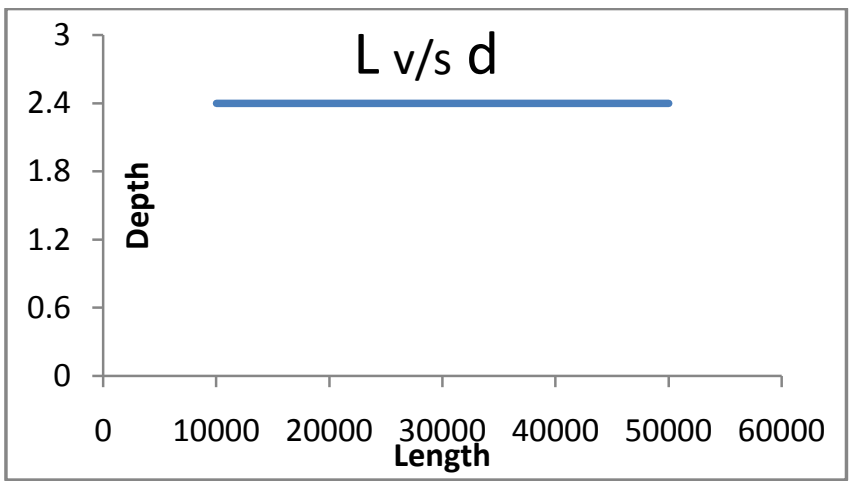

Fig 2.11: $\mathrm{L}$ vs $\mathrm{d}$

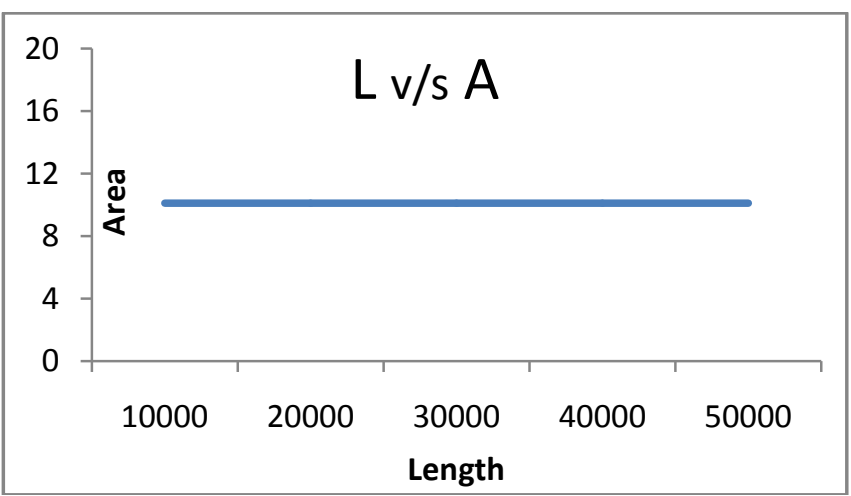

Fig 2.12: $\mathrm{L}$ vs $\mathrm{A}$

\subsection{Case 4: Keep Q, S and $L$ constant, vary $n$.}

Keeping $\mathrm{Q}=10$ cumecs, $\mathrm{L}=10000, \mathrm{~S}=0.0002$ and varying roughness coefficient (shown in table 4), various optimal parameters and optimal cost of canal are found out.

Table 4

\begin{tabular}{|c|c|c|c|c|c|c|c|}
\hline $\begin{array}{c}\mathrm{N} \\
\text { varies }\end{array}$ & $\mathrm{d}$ & $\mathrm{R}$ & $\mathrm{V}$ & $\mathrm{A}$ & $\mathrm{P}$ & $\mathrm{B}_{\mathrm{b}}$ & $\mathrm{Z}_{\mathrm{z}}$ \\
\hline 0.014 & 2.26 & 1.13 & 1.10 & 9.10 & 8.1 & 2.40 & $9.7 \mathrm{E}+006$ \\
0.015 & 2.32 & 1.16 & 1.04 & 9.60 & 8.3 & 2.40 & $9.95 \mathrm{E}+006$ \\
0.016 & 2.38 & 1.19 & 0.99 & 10.1 & 8.5 & 2.44 & $1.02 \mathrm{E}+007$ \\
0.017 & 2.44 & 1.22 & 0.95 & 10.5 & 8.7 & 2.47 & $1.04 \mathrm{E}+007$ \\
\hline
\end{tabular}

Figure 2.13 and 2.15 show that the depth and area increases linearly with the increase in value of roughness coefficient. Figure 2.14 show that velocity decreases whereas in figure 2.16 total cost of canal increases with the increase in $\mathrm{n}[3,4]$.

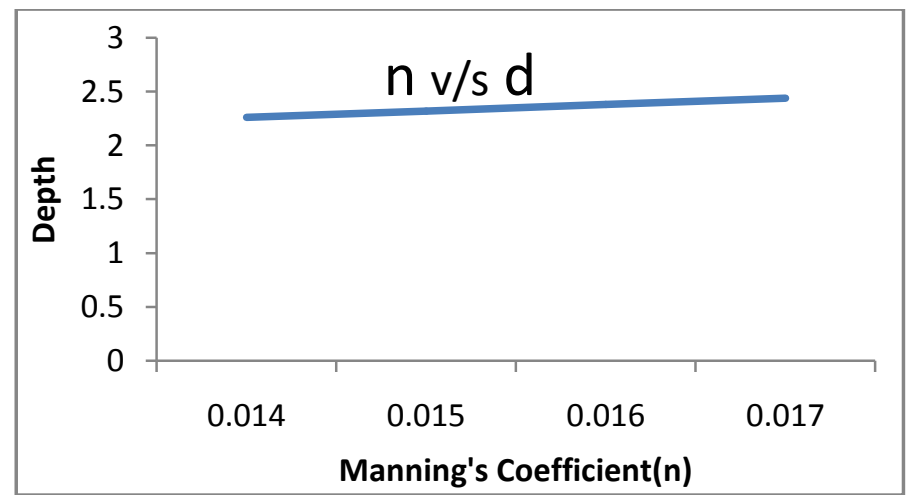

Fig 2.13: $n$ vs $d$

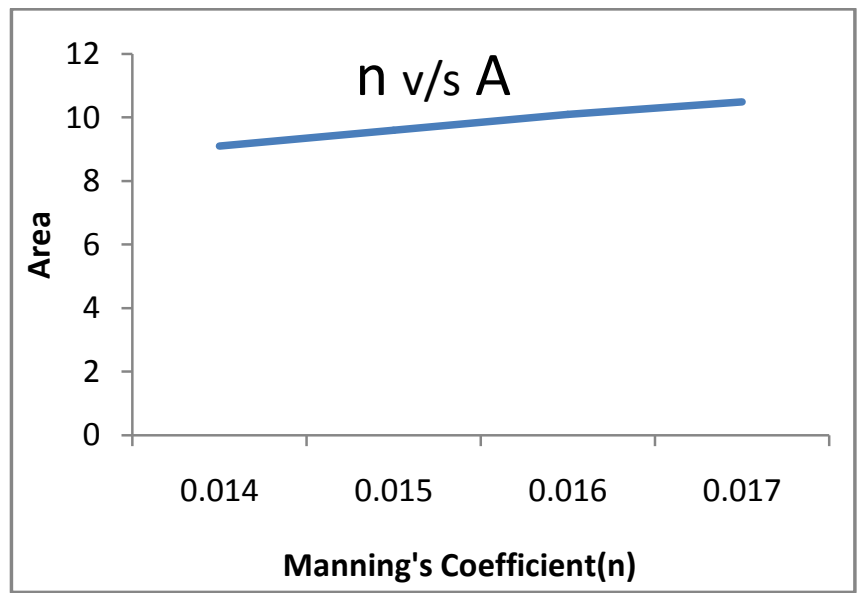

Fig 2.14: $\mathrm{n}$ vs A 


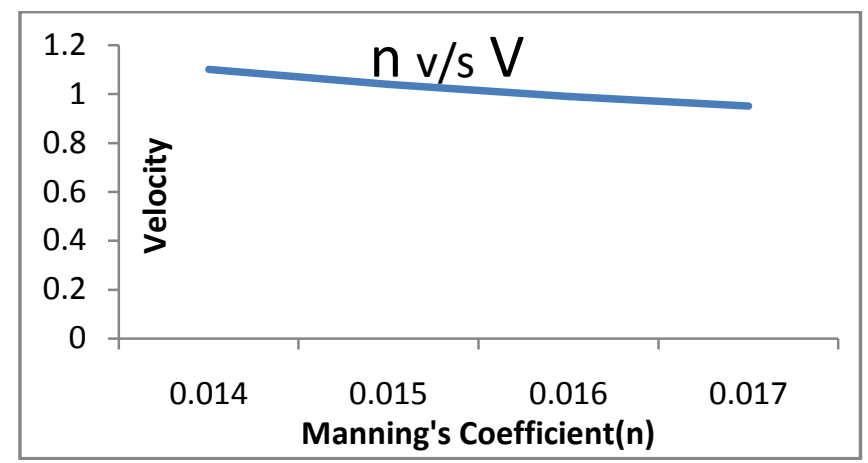

Fig 2.15: $n$ vs V

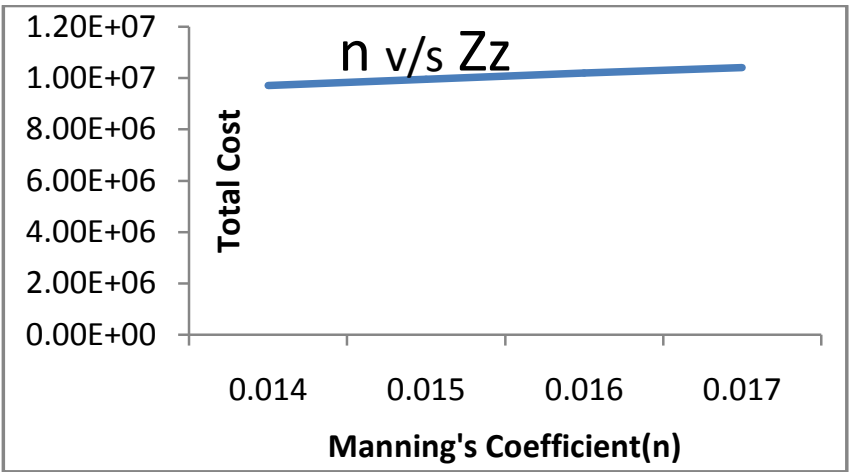

Fig 2.16: $\mathrm{n}$ vs $\mathrm{Z}_{\mathrm{Z}}$

\section{CONCLUSIONS}

- The optimal depth of canal remains constant for all values of length and decreases with increase in slope whereas it increases with increase in discharge and roughness coefficient.

- The optimal cost of canal decreases with increase in slope of canal and increases with increase in discharge, length and roughness coefficient.

- Velocity of canal remains constant as length of canal increases and decreases with increase in roughness coefficient and increases with increase in discharge and slope of canal.

- Area of canal increases when discharge and roughness coefficient increases and decreases with increasing slope. It remains constant in case of varying length.

\section{REFERENCES}

[1]. Varshney, Theory and Design of Irrigation Engineering, Nem Chand \& Bros., 1979.

[2]. Ravichandran, Programming with $\mathrm{C}++$, Tata McGraw-Hill Education, 2011.

[3]. S.K.Garg, Irrigation and Hydraulics Structures, Khanna, 2009.

[4]. B.C. Punmia and Pande Brij Bansi Lal, Irrigation and Water Power Engineering, Standard Publishers Distributor. 